\title{
WILLINGNESS-TO-PAY AND PREFERENCE HETEROGENEITY FOR SERVICE ATTRIBUTES OF SOLID WASTE MANAGEMENT: AN EXPERIENCE IN KOLKATA, INDIA
}

\author{
HAZRA T. ${ }^{1, *}$ \\ GOEL $S^{2}$ \\ MAITRA B. ${ }^{3}$
}

\author{
Civil Engineering Department, Jadavpur University \\ Kokata-700032, India \\ Civil Engineering Department, Indian Institute of Technology \\ Kharagpur, Kharagpur-721302, India
}

Received: 26/06/2014

Accepted: 01/10/2014

Available online: 03/12/2014 *to whom all correspondence should be addressed: e-mail: tumpa hazra@yahoo.com

\section{ABSTRACT}

The effects of various socioeconomic characteristics on Willingness-to-Pay (WTP) values for service attributes of Solid Waste Management (SWM) were evaluated in this study. The Stated Choice (SC) data collected from respondents in the Kolkata Municipal Corporation (KMC) area, India were analyzed using Random Parameter Logit (RPL) models. Education and household income were found to have statistically significant decomposition effects on mean estimates of several SWM attributes. High income and/or high education were well-correlated to higher WTP values for most of the service attributes. The results show that due consideration to socioeconomic characteristics is necessary while formulating measures for improvement of SWM service in an urban area. This work also demonstrates potential application of RPL models for investigating the effect of socioeconomic characteristics on WTP values, and successful application of constrained triangular distribution in RPL models.

Keywords: Solid waste management, stated choice, random parameter logit model, constrained triangular distribution, heterogeneity

\section{Introduction}

Over the last few decades, the generation of Solid Waste (SW) in urban areas has increased significantly due to rapid growth of urban population, increase in per capita income and increasing production as well as consumption patterns. The urban population in Asia generates around $0.760 \times 10^{6}$ tons of Municipal Solid Waste (MSW) per day, and this is expected to increase to $1.8 \times 10^{6}$ tons by 2025 (Pokhrel and Viraraghavan, 2005). Simultaneously, availability of land for assimilation of this waste is decreasing fast making Solid Waste Management (SWM) in urban areas a major concern for urban authorities. The estimated land requirement for disposal of huge amounts of Solid Waste (SW) in India would be $169.6 \mathrm{sq}$. $\mathrm{kms}$ in 2047 as compared to $20.2 \mathrm{sq}$. kms in 1997 (CPCB, $2000 \mathrm{a}$ and b). There are additional problems associated with SWM in developing countries such as India due to irregular collection, use of uncovered container and transfer vehicle, lack of treatment and unscientific disposal. Lacunae associated with SWM contribute significantly towards increase in air, water and soil pollution levels, as well as health problems (Contreras et al., 2008). In most developing countries, financial resources available for SWM are inadequate and urban authorities need suitable policies and measures for improving SWM process without adding to the financial burden of the Government. In this context, it is necessary to understand households' Willingness-to-Pay (WTP) for change in SWM service attributes which is likely to have an 
impact on both users cost (or households cost) and financial cost to the Government. Although several studies have been reported in the literature on WTP estimates in various contexts (Basu and Maitra, 2007 for valuing attributes of enhanced traffic information; Hensher and Sullivan, 2003 for WTP of road curviness and road type; Phanikumar and Maitra, 2010 for modeling generalized cost of travel and its application for improvement of taxies in developing countries considering Kolkata, India as a case study), Hasan et al., 2011 for understanding house level evacuation during Hurricane considering Hurricane Ivan as a case study, adequate investigations have not been carried out on valuation of SWM attributes by households, especially in developing countries such as India. Hazra et al., (2013) reported WTP of households towards SWM attributes in Kolkata Municipal Corporation (KMC) area, India using a Multinomial Logit (MNL) model. However, WTP values may be influenced by socioeconomic characteristics of households and it is important to understand such influences, if any, especially in cities of India where the household composition is highly heterogeneous in terms of income, education, etc. Therefore, the database reported by Hazra et al., (2013) is further analysed by developing several Random Parameter Logit (RPL) models in order to understand the difference in WTP values obtained from MNL and RPL models and to capture the decomposition effect of socioeconomic characteristics of households, if any, on WTP values.

\subsection{Study Area}

The study area includes about $187 \mathrm{~km}^{2}$ geographical area of Kolkata Municipal Corporation (KMC) with a population of 4,486, 679 (Census, 2011). KMC area generates Municipal Solid Waste (MSW) at the rate of $0.632 \mathrm{~kg}$ per capita per day (Hazra and Goel, 2009). The process of SWM in KMC area is highly labourintensive. Solid Waste (SW) from road sweeping and door-to-door collection is stored in uncovered containers. So far, about $60 \%$ of the core city area of $\mathrm{KMC}$ is provided with door-to-door collection facility. In the remaining area, households dispose their waste to the nearest storage containers or community bins. The collection frequency is not uniform throughout the area and overflowing storage containers are common in the city. The uncovered vehicles transfer wastes from collection points to disposal site. No segregation (except recyclable dry) of SW is done at home and rag-picking is common at each step of the SWM system.

\section{Methodology}

Valuation of attributes may be carried out using Stated Preference (SP) and or Revealed Preference (RP) data. SP data and models are recognized as rich and effective for estimation of WTP values (Hensher and Sullivan, 2003). Several studies have also used SP data for estimation of economic value of various SWM service attributes such as recycling and landfilling (Bluffstone and Shazo, 2003; Caplan et al., 2002; Karousakis and Birol, 2007; Sakata, 2007; Sasao, 2004; Shinkuma, 2003). The WTP values reported in the present work were obtained by analyzing SP data collected from households in the KMC area. Discrete Choice Experiment (DCE) method was adopted for collecting SP data from households as they provide a framework for studying the relative marginal disutility of variations in attributes and their potential correlations (Louviere et al., 2000), and have also been used extensively (Basu and Maitra, 2007; Das et al., 2008; Hazra et al., 2013; Jin et al., 2006; Phanikumar and Maitra, 2010).

In the present work, SP data is analyzed by employing RPL models. The decomposition effects of household characteristics on the mean estimates of random parameters are also investigated in RPL models. Although, the theory of RPL models is documented in the literature (McFadden and Train, 2000; Train, 2003), a brief outline of RPL model is included below in the context of the present work.

\subsection{Theoretical background}

McFadden and Train (2000) mentioned that an RPL model is a highly flexible model that can approximate any random utility model.

The basic utility model of MNL is

$u_{\text {in }}=\beta_{n} x_{\text {in }}+\varepsilon_{\text {in }}$ 
where $u_{\text {in }}$ is the utility of the $i^{\text {th }}$ alternative for individual $n, \beta_{n}$ is the coefficient vector for each individual, $\mathrm{x}_{\mathrm{in}}$ is the full vector of explanatory variables and $\varepsilon_{\text {in }}$ is the error term.

There is a need to introduce a conventional form of heterogeneity of preferences to understand the interactions between alternative attributes and individual socioeconomic characteristics such as gender, age, education level, income level, existing solid waste management systems etc. In this case, the parameter of each attribute is required to be a function of the individuals' observed socioeconomic characteristics which enables to detect the systematic variations in tastes. However, on many occasions individual information is not available, or tastes may vary with socioeconomic characteristics that are difficult to measure or cannot be observed. In such cases, Eq. (1) can be generalized to consider heterogeneity specifying random parameters for each individual. Thus, the utility of alternative $i$ for an individual $n$ would be

$u_{\text {in }}=\beta_{n} x_{\text {in }}+\varepsilon_{\text {in }}=\beta_{1} x_{\text {in }}+\beta_{1 n} x_{\text {in }}+\varepsilon_{\text {in }}$

Thus, each individual's coefficient vector $\beta_{n}$ is the sum of the population mean $\beta_{1}$ and individual deviation $\beta_{1 n}$ from the average value for the population. $\beta_{1 n} x_{i n}$ is the error component that induces heteroskedasticity in the unobserved portion of the utility. This implies an important implication of RPL specification where it is not necessary to assume that the IIA property holds. In Eq. (2), $x_{\text {in }}$ are observed variables that relate to the alternative and individual, and $\beta_{n}$ is a vector of coefficients of these variables for individual $n$. Let the coefficients vary over individuals in the population with density $f\left(\beta_{n} \mid \theta\right)$, where $\theta$ represent the mean and covariance of $\beta_{n}$ in the population and if the error term $\varepsilon_{\text {in }}$ follows the IID type I extreme value distribution, then the model is called Mixed Logit (ML) random parameter model (Train, 2003) because then the choice probability is the mixture of logits with $f$ as mixing distribution (Hensher et al., 2005).

In this case, the individual knows the value of her/his own $B_{n}$ and $\varepsilon_{i n}$ s for all $i$ and chooses alternative $i$ if and only if $\operatorname{Uin} \geq \operatorname{Ujn}$ for all $J \in C n, \forall j \neq i$. On the other hand, the modeler observes $x_{i n} s$ but not $B_{n}$ or the $\varepsilon_{i n}$. If the modeler observed $B_{n}$, then the choice probability would be standard logit, since the $\varepsilon_{i n}$ sare IID type I extreme value distribution. Then the probability, conditional on $B_{n}$ is

$$
L_{n}\left(\beta_{n}\right)=\frac{\exp \left(\beta_{n} x_{i n}\right)}{\sum_{i=1}^{J} \exp \left(\beta_{n} x_{i n}\right)}
$$

However, the modeler does not know $B_{n}$, and therefore cannot condition. Therefore, the unconditional choice probability is the integral of $L_{n} B_{n}$ over all possible variables of $B_{n}$ (Train, 2003).

$$
P_{\text {in }}=\int\left(\frac{\exp \left(\beta_{n} x_{i n}\right)}{\sum_{i=1}^{j} \exp \left(\beta_{n} x_{i n}\right)}\right) f\left(\beta_{n} \mid \theta\right) d \beta_{n}
$$

Since the integral in Eq. (4) cannot be evaluated analytically, exact maximum likelihood estimation is not possible. Instead, the probability is approximated through simulation (Brownstone and Train, 1999). Maximization is then conducted on the simulated log-likelihood function, generally using Halton draws (Train, 1999).

\subsection{Selection of Distribution}

In RPL model, it is necessary to make an assumption regarding the distribution of each of the random coefficients. The choice of distribution is often limited by difficulty of model estimation and availability of econometric software. In the present work, constrained triangular distribution is assumed for random parameters in RPL models. Constrained triangular distribution is basically a generalization of the uniform distribution with a peak in the density function and two endpoints fixed at zero and $2 \times$ mean (Basu and Maitra, 2006; Pahnikumar and Maitra, 2010). 


\subsection{Survey Instrument and Database}

Survey instruments included respondent's socioeconomic characteristics, and Stated Preference 'choice' from the choice set. Six attributes of SWM were included and described by suitable levels. Attribute-I included 'Method of disposal of SW by households' and was described by three levels namely (i) directly to the person collecting SW from households (Door-to-Door), (ii) to private bins provided by KMC within building premises (Private Bin), and (iii) to community bins provided by KMC outside building premises (Community Bin). Attribute-II included 'Walking time for disposal of waste by households' and was described by four levels as 0, 2, 4, 6 minutes. Zero walking time was applicable for 'Door-to-Door' and 'Private Bin'. Attribute-III included 'Type of storage bin and transfer vehicle' and was described by two levels namely uncovered and covered. Segregation of waste at home (i.e. Attribute-IV) was described by three levels namely, (i) No segregation, (ii) segregation as biodegradable and non-biodegradable, and (iii) segregation as biodegradable, recyclable wet and the rest. Two levels (i.e. High and Moderate) were used to describe 'Clearance frequency of waste from households or bins' (i.e. Attribute-V). High clearance frequency included daily door-to-door collection and regular collection from bins without any spill over, while moderate clearance frequency included alternate day door-to-door collection and frequent collection from bins with occasional spill over. The yearly municipal tax paid by household was added as another attribute (i.e. Attribute-VI) as a representation of direct cost to households. The levels included were $20 \%, 15 \%, 10 \%$ and $5 \%$ lower than the present municipal tax, 5\% and $10 \%$ higher than the present and also the present municipal tax.

SPSS 7.5 was used to generate 30 choice sets based on fractional factorial orthogonal main effects only (Hazra et al., 2013; Hensher et al., 2005; Louviere et al., 2000) without loss of statistical properties of full factorial design. To reduce the confusion and/or fatigue of respondents, these 30 choice sets each having three alternatives were randomly grouped into 6 blocks, each containing 5 hypothetical choice sets.

In order to develop the database, paper-pencil based interviews were carried out to obtain socioeconomic characteristics of respondents and their choices. Respondents were intercepted randomly at various strategic locations in KMC area during May to July 2009. During data collection, responses were collected from 529 respondents where 667 people were actually approached. Respondents were requested to provide their socio economic data and data related SWM system existed in their locality. They were also requested to choose one alternative among three alternatives of each choice set. Each questionnaire consisted of 5 choice set each having three alternatives. However, some of the responses were omitted during initial screening mainly due to incompleteness of information. Finally, 2464 refined observations were retained in the database for model development purpose. In the process of database development, all the data were coded according to their levels. The attributes 'walking time during disposal' and 'yearly municipal tax' were entered in cardinal linear form (i.e., in continuous scale). The qualitative attributes such as 'type of storage bin and transfer vehicle', 'segregation of waste at home' and 'clearance frequency' were effect-coded.

\subsection{Model}

LIMDEP (8.0) was used to analyse the Stated Choice (SC) data using RPL models. In RPL models all the parameters except the cost was assumed as random. RPL models have a tendency to become unstable when all attributes are allowed to vary (Ruud, 1996). This problem can be resolved by fixing the cost parameter. The Alternative Specific Constant (ASC) s were also considered as non-random or fixed. In the present work, the random parameters were assumed to be constrained triangularly distributed (Basu and Maitra, 2006; Pahnikumar and Maitra, 2010). A simulated maximum likelihood estimator, using Halton draws with 500 replications, was used to estimate the models (Train, 1999). The effect of socioeconomic characteristics of respondents on the mean estimates of random parameters was also investigated in RPL models. 


\section{Results and discussion}

The effects of various socioeconomic attributes of households/respondents on mean estimates of random parameters were investigated using RPL models. However, only 'family income of household' and 'education level of respondent' indicated statistically significant decomposition effects on the mean estimates of some of the random parameters. Four RPL models used for analyzing the SC data are reported in Table 1.

The MNL model as reported by Hazra et al., (2013) is also included in Table 1 for comparison purposes. RPL-I did not consider the effect of heterogeneity of socioeconomic attributes on mean estimates of random parameters. RPL-II included the effect of 'family income' on mean estimates of some of the parameters. Households with a monthly family income below ₹ 20,000 (USD 432.9) were considered as Low Income (LI) group, while the others were considered as High Income (HI) group (1USD = ₹ 46.2). RPLIII included the decomposition effects of respondents' education level on the mean estimates of some of the random parameters. Respondents with education level below graduation were considered as Low Education (LE) group, while others (i.e. with education level as graduation or higher) were considered as High Education (HE) group. RPL-IV included combined effects of income and education levels on mean estimates of some of the random parameters. As all the random parameters of all the four RPL models were assumed to be constrained triangularly distributed, the spreads of random parameters are not reported separately in Table 1.

It may be observed from Table 1 that most of the parameter estimates are statistically significant at $95 \%$ or $90 \%$ level. For some of the effect coded attributes, either the mean estimates or the decomposition effect on mean estimates were found statistically insignificant. These statistically insignificant estimates were neglected during WTP calculation. The signs of the parameter estimates for cardinal linear variables are logical. For example, the negative sign associated with coefficient estimates of 'Walking Time' or 'Yearly Municipal Tax' indicates that an increase in the value of these variables increases the disutility. For each effect coded variable, the change in utility or disutility due to a shift from one level to another is also logical. For example, a change in the level of attribute 'type of storage bin and transfer vehicle' from 'covered' to 'uncovered' is considered as disutility. Also, a change in the level of the attribute 'clearance frequency of waste' from 'high' to 'moderate' is also considered as disutility. Two levels of the attribute 'Segregation of waste at home', namely, 'no segregation' and 'segregation as biodegradable and nonbiodegradable' are considered as utility as compared to 'segregation as biodegradable, recyclable and the rest'. Also, 'no segregation' is considered as more utility that 'segregation as biodegradable and nonbiodegradable'. The estimates obtained for different levels of the attribute 'Segregation of waste at home' are consistent with the present practice of doing no segregation of SW (except for recyclable dry) in homes in KMC area. The ASC values are also found logical as 'disposal of waste to private bin' is considered disutility as compared to 'door-to-door collection'and the disutility increases for a shift from 'private bin collection' to 'community bin disposal'.

It is interesting to note that the disutility associated with walking time to community bins increases with an increase in education level and/or household income level. Also, a shift of the level of attribute 'type of storage bin and transfer vehicle' from 'covered' to 'uncovered' is considered as more disutility when education level or household income level is high. Similar interpretation can be made on the effect of education or income level on 'collection frequency of waste'. Family income level is found to have statistically significant decomposition effects on mean estimates of all levels of 'segregation of waste at home'. On the contrary, 'education level' indicated statistically insignificant effect on mean estimate of the level 'no segregation'. When both income level and education level were considered in RPL-IV, education level did not indicate statistically significant decomposition effect on any level of attribute 'segregation of waste at home'.

The adjusted $\rho^{2}$ values of all the RPL models also indicate that these models are acceptable in terms of overall goodness-of-fit. 
Table 1. Coefficient Estimates of MNL and RPL Models

\begin{tabular}{|c|c|c|c|c|c|}
\hline Attribute & MNL Coeff. & RPL- I Coeff. & RPL- II Coeff. & RPL- III Coeff. & RPL- IV Coeff. \\
\hline & & \multicolumn{4}{|c|}{ Random Parameters } \\
\hline \multirow{2}{*}{ Walking time } & -0.547 & -0.941 & -0.667 & -0.650 & -0.579 \\
\hline & $(-13.41)$ & $(-6.88)$ & $(-6.36)$ & $(-6.14)$ & $(-5.99)$ \\
\hline Covered & 0.344 & 0.364 & 0.261 & 0.138 & 0.117 \\
\hline Collection/Storage//Transfer & $(4.92)$ & $(4.30)$ & $(3.10)$ & $(1.66)$ & $(1.37)^{*}$ \\
\hline \multirow{2}{*}{ S1 } & 0.442 & 0.455 & 0.415 & 0.486 & 0.479 \\
\hline & $(5.71)$ & $(4.93)$ & $(4.33)$ & $(4.38)$ & $(4.32)$ \\
\hline \multirow{2}{*}{ S2 } & 0.215 & 0.179 & 0.351 & 0.421 & 0.465 \\
\hline & $(2.51)$ & $(1.66)$ & $(3.08)$ & $(3.14)$ & (3.49) \\
\hline \multirow{2}{*}{ High collection frequency } & 0.374 & 0.403 & 0.206 & 0.151 & 0.091 \\
\hline & $(7.75)$ & $(7.04)$ & $(3.35)$ & $(2.18)$ & $(1.25)^{*}$ \\
\hline & & \multicolumn{4}{|c|}{ Non-random Parameters } \\
\hline \multirow{2}{*}{ Cost or Municipal tax } & -0.00360 & -0.00414 & -0.00418 & -0.00418 & -0.00429 \\
\hline & $(-16.18)$ & $(-14.99)$ & $(-15.96)$ & $(-15.82)$ & $(-16.29)$ \\
\hline \multirow{2}{*}{ ASC to Private Bin } & -0.586 & -1.248 & -0.675 & -0.830 & -0.617 \\
\hline & $(-3.78)$ & $(-4.21)$ & $(-2.69)$ & $(-3.32)$ & $(-2.57)$ \\
\hline \multirow{2}{*}{ ASC to Community Bin } & -0.784 & -1.497 & -1.133 & -1.186 & -1.068 \\
\hline & $(-3.60)$ & $(-3.97)$ & $(-3.41)$ & $(-3.68)$ & $(-3.42)$ \\
\hline & & & \multicolumn{3}{|c|}{ Heterogeneity in Mean } \\
\hline \multirow{2}{*}{ Walking time: Inc } & & & -0.263 & - & -0.214 \\
\hline & & & $(-5.33)$ & & $(-3.95)$ \\
\hline Covered Collection/Storage & & & 0.416 & - & 0.203 \\
\hline /Transfer: Inc & & & (4.81) & & $(2.17)$ \\
\hline \multirow{2}{*}{ S1: Inc } & & & 0.568 & - & 0.586 \\
\hline & & & $(5.26)$ & & $(4.96)$ \\
\hline \multirow{2}{*}{ S2: Inc } & & & -0.748 & - & -0.729 \\
\hline & & & $(-4.14)$ & & $(-3.66)$ \\
\hline \multirow{2}{*}{ High collection frequency: Inc } & & & 0.576 & - & 0.411 \\
\hline & & & $(6.30)$ & & $(4.20)$ \\
\hline \multirow{2}{*}{ Walking time: Edu } & & & - & -0.204 & -0.123 \\
\hline & & & & $(-5.12)$ & $(-2.81)$ \\
\hline \multirow{2}{*}{$\begin{array}{c}\text { Covered } \\
\text { Collection/Storage/Transfer: Edu }\end{array}$} & & & - & 0.490 & 0.450 \\
\hline & & & & $(6.86)$ & $(5.80)$ \\
\hline \multirow{2}{*}{ S1: Edu } & & & - & 0.148 & -0.051 \\
\hline & & & & $(1.36)^{*}$ & $(-0.43)^{*}$ \\
\hline \multirow[t]{2}{*}{ S2: Edu } & & & - & -0.317 & -0.084 \\
\hline & & & & $(-2.0)$ & $(-0.49)^{*}$ \\
\hline \multirow{2}{*}{ High collection frequency: Edu } & & & - & 0.473 & 0.343 \\
\hline & & & & $(6.13)$ & $(4.11)$ \\
\hline Observations & 2464 & 2464 & 2464 & 2464 & 2464 \\
\hline Log Likelihood & -2089.129 & -2086.350 & -2043.754 & -2020.752 & -1999.797 \\
\hline Adjusted $\rho^{2}$ & 0.169 & 0.170 & 0.186 & 0.195 & 0.203 \\
\hline
\end{tabular}

Note: t-values are in parentheses; *Parameter estimate is statically insignificant; MNL Coeff.: Model coefficients obtained from MNL mode already specified in Hazra et al., 2013; RPL-I Coeff: Model coefficients obtained from RPL-I model which did not consider the effect of heterogeneity of socioeconomic attributes on mean estimates of random parameters; RPL-II Coeff.: Model coefficients obtained from RPL-I I model which included the effect of 'family income' on mean estimates of some of the parameters; RPL-III Coeff: Model coefficients obtained from RPL-III model which included the decomposition effects of respondents' education level on the mean estimates of some of the random parameters; RPL-IV Coeff.: Model coefficients obtained from RPL-IV model which included combined effects of income and education levels on mean estimates of some of the random parameters; S1: no segregation of waste at home; S2: segregation of waste in biodegradable and nonbiodegradable fraction at home; Inc: Income; Edu: Education; ASC to Private Bin: Alternative Specific Constant to Private Bin; ASC to Community Bin: Alternative Specific Constant to Community Bin; Walking time:Inc: Effect of Income on walking time; Covered Collection/Storage/Transfer: Inc: Effect of Income on Covered collection/ storage of transfer system; S1: Inc: Effect of Income on no segregation of waste at home; S2:Inc: Effect of income on segregation of waste in biodegradable and non-biodegradable fraction at home; High collection frequency: Inc: Effect of income on Collection frequency; Walking time: Edu: Effect of education on walking time; Covered Collection/Storage/Transfer: Edu: Effect of education on Covered collection/ storage of transfer system; S1: Edu Effect of education on no segregation of waste at home; S2:: Edu: Effect of education on segregation of waste in biodegradable and non-biodegradable fraction at home; High collection frequency: Edu: Effect of education on Collection frequency; 
It may be observed that in the present case study, no significant improvement in adjusted $\rho^{2}$ is observed between MNL and RPL-I models, possibly due to the assumption of constrained triangular distribution for random parameters.

An improvement in adjusted $\rho^{2}$ value is however, observed when heterogeneity (based on monthly family income and/ or education) was considered in RPL models. While RPL-II and RPL-III were found superior to RPL-I, the highest adjusted $\rho^{2}$ value is obtained in RPL-IV which included the decomposition effects of both income and education. In the present case, parameter richer models are found superior in terms of overall goodness-of-fit (i.e. adjusted $\rho^{2}$ value). This observation is consistent with the observations made by other researchers (Basu and Maitra, 2007; Pahnikumar and Maitra, 2010).

The interpretation of model coefficients is not straightforward except for significance. Therefore, the marginal rates of substitution between the attributes and cost are calculated. With a fixed cost coefficient and triangularly distributed attributes, marginal WTP is also triangularly distributed. The ratio of parameter estimate for walking time over parameter estimate for SWM cost (yearly municipal tax) is the estimated mean subjective value of walking time attribute for reduction in one minute walking time. In the case of qualitative attributes, the WTP values are reported for a shift from one level to another. A comparison of WTP values obtained from MNL and RPL-I models is given in Table 2. It may be observed from Table 2 that WTP values obtained from MNL and RPL-I models are different. However, no systematic gain or loss in WTP is observed between the two model specifications. Higher or lower WTP values from RPL models have also been reported by other researchers in various contexts such as household appliance study (Revelt and Train, 1997), recreational demand estimation (Train, 1998), mode choice modeling (Alpizar and Carlsson, 2001; Bhat, 1998), estimation of value of travel time (Algers et al., 1998; Carlsson, 1999) and modeling generalized cost of travel for improvement of taxies in Kolkata (Phanikumar and Maitra, 2010).

Table 2. Willingness-to-Pay Values for SWM Service Attributes

\begin{tabular}{cccccc}
\hline Model & $\begin{array}{c}\text { Per Minute Walking } \\
\text { Time to Community Bin } \\
\text { (₹ /Year) }\end{array}$ & $\begin{array}{c}\text { Covered Collection, } \\
\text { Storage \&Transfer } \\
\text { (₹ /Year) }\end{array}$ & $\begin{array}{c}\text { High frequency } \\
\text { of Collection } \\
\text { (₹ /Year) }\end{array}$ & $\begin{array}{c}\text { S1 instead of } \\
\text { S2 at Home } \\
\text { (₹ /Year) }\end{array}$ & $\begin{array}{c}\text { S1 instead of } \\
\text { S3 at Home } \\
\text { (₹ /Year) }\end{array}$ \\
\hline MNL & 152 (USD 3.3) & 191 (USD 4.1) & 208 (USD 4.5) & 63 (USD 1.4) & 305 (USD 6.6) \\
RPL-I & 227 (USD 4.9) & 175 (USD 3.8) & 195 (USD 4.2) & 67 (USD 1.5) & 263(USD 5.7) \\
\hline
\end{tabular}

S1: No Segregation; S2: Segregation as biodegradable and non-biodegradable;

S3: segregation as biodegradable, recyclable wet and the rest

$1 U S D=₹_{46.2}$

WTP values were also calculated for different income and education levels as per RPL-II, III and IV.

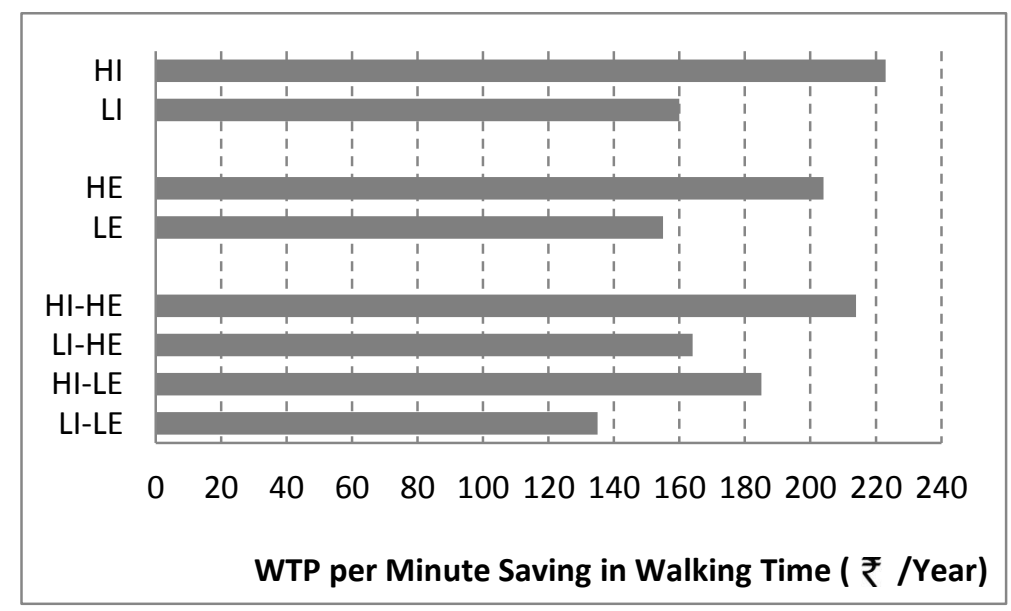

Figure 1. Variation of WTP for Saving in Walking Time to Community Bin

$\mathrm{LI}=$ Low income, $\mathrm{HI}=\mathrm{High}$ income, $\mathrm{LE}=$ Low education, $\mathrm{HE}=$ High education, $1 \mathrm{USD}=₹ \mathbf{4 6 . 2}$ 
Figure 1 shows the variation of WTP for a reduction in walking time across different income and education levels.

The results indicate higher WTPs for high family Income (HI) and/or high education (HE) as compared to low family income (LI) and/or low education (LE). In fact, HI-HE indicates 1.6 times higher WTP than LI-LE for a reduction in walking time to community bins. The variation of WTP justify the need for giving due consideration to family income and education levels while locating community bins in various parts of the Kolkata city.

The variation of WTP across different socio-economic groups for covered storage bin and transfer vehicle is shown in Figure 2. The results indicate that the WTP for HI is 2.6 times higher than LI. HE indicates 4.5 times higher WTP than LE. When income and education levels are considered together, LI-LE indicates no WTP for improvement in type of storage bin and transfer vehicle. On the contrary, the WTP is found as high as ₹305 per year (USD 6.6 per year) for HI-HE.

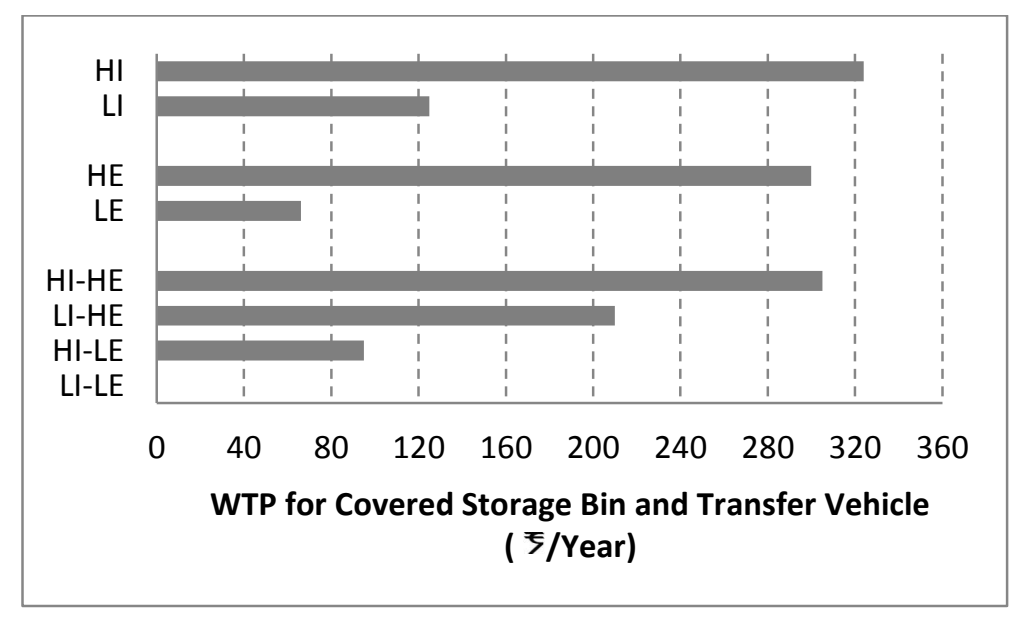

Figure 2. Variation of WTP for Covered Storage Bin and Transfer Vehicle

$\mathrm{LI}=$ Low income, $\mathrm{HI}=$ High income, $\mathrm{LE}=$ Low education, $\mathrm{HE}=$ High education, $1 \mathrm{USD}=$ ₹ 46.2

The variation of WTP for high clearance frequency of waste across different socioeconomic groups is shown in Figure 3. In general, HI or HE indicates significantly higher WTP as compared to LI or LE. When income and education levels are considered together, the LI-LE indicates no WTP for high clearance frequency of waste. Among other groups, HI-HE indicates higher WTP than HI-LE and LI-HE.

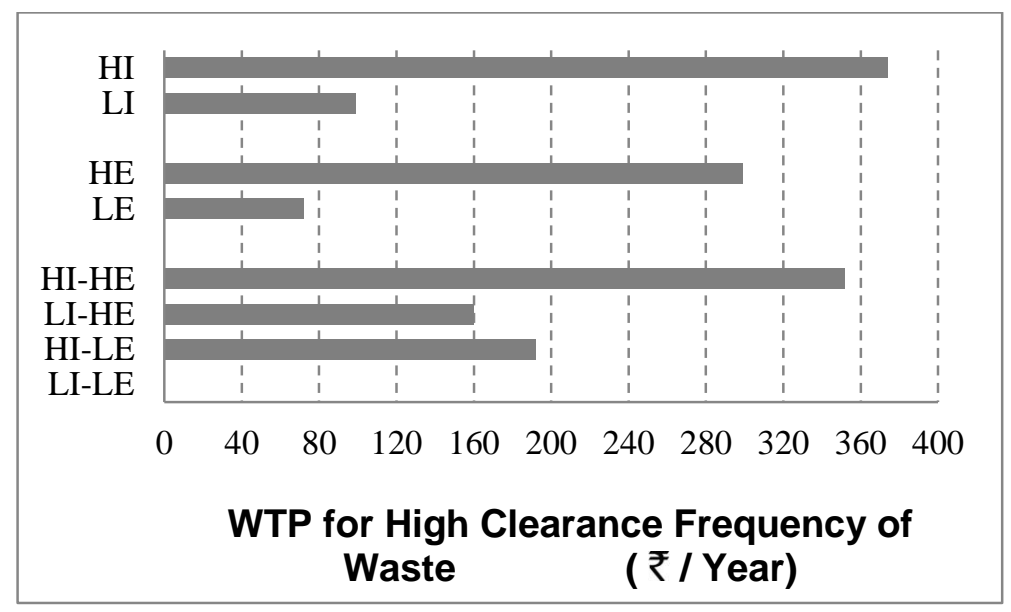

Figure 3. Variation of WTP for High Clearance Frequency of Waste $\mathrm{LI}=$ Low income, $\mathrm{HI}=$ High income, $\mathrm{LE}=$ Low education, $\mathrm{HE}=$ High education, $1 \mathrm{USD}=₹ \mathbf{4 6 . 2}$ 
The variation of WTP for changes in level of segregation of waste at home across different socio-economic groups is shown in Figure 4. Change in household income rather than change in education level is found to have a major influence on the WTP for a shift from 'segregation as biodegradable and nonbiodegradable' to 'no segregation'. It is interesting to note that LE rather than HE results in higher WTP for 'segregation as biodegradable, non-biodegradable and the rest' to no segregation. This may be due to the inconvenience to the households with less education to segregate waste into three distinguished fractions. Further, the WTP for LI categories (say, LI, LI-LE and LI-HE) is practically insignificant. An increase in household income is found to indicate higher WTP for a shift from 'segregation as biodegradable, recyclable and the rest' to 'no segregation', but even for LI-LE, the WTP is found to be as high as ₹ 332 per year (USD 7.2 per year).

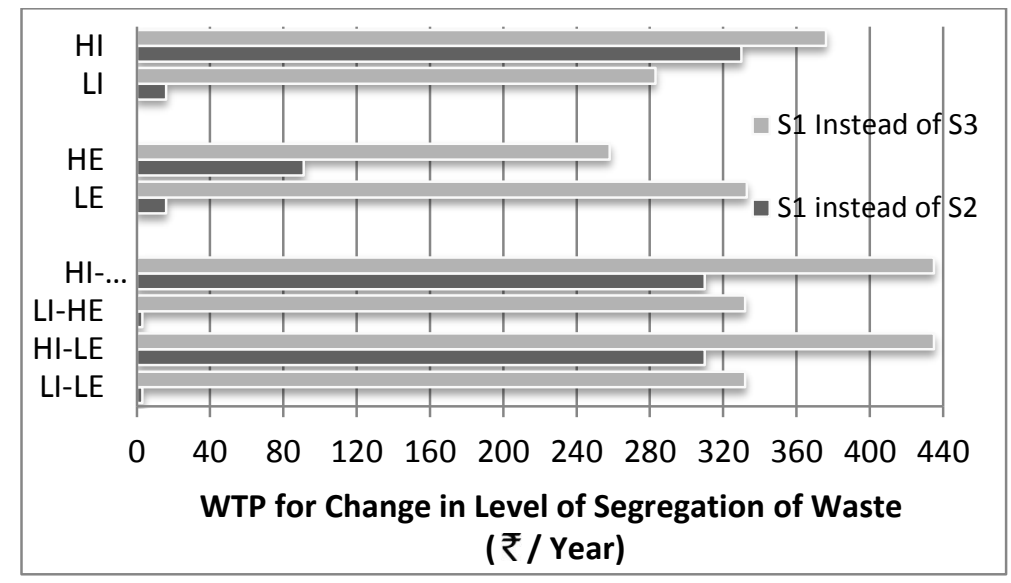

Figure 4 Variation of WTP for Change in Level of Segregation of Waste at Home

$\mathrm{LI}=$ Low income, $\mathrm{HI}=\mathrm{High}$ income, $\mathrm{LE}=$ Low education, $\mathrm{HE}=$ High education, $1 \mathrm{USD}=₹ \mathbf{4 6 . 2}$

S1: No Segregation; S2: Segregation as biodegradable and non-biodegradable; S3: Segregation as biodegradable, recyclable wet and the rest

The variation of WTP for different socioeconomic groups with respect to change in segregation levels, as reported in Figure4, indicate that it is necessary to duly consider socio-economic characteristics while recommending a change in the current practice of doing 'no segregation' at home. The findings also indicate that it may be necessary to provide suitable tax relaxation compatible with WTP, if some level of segregation at home is recommended in the Kolkata city.

\section{Conclusions}

The present work brings out findings related to the effect of socio-economic characteristics on WTP values for Solid Waste Management (SWM) attributes in Kolkata Municipal Corporation (KMC) area. Education and family income levels are found to have statistically significant decomposition effects (more than 95\%) on mean estimates of several attributes and their levels. No segregation of waste instead of segregation of waste in biodegradable, recyclable wet and rests fraction at home was highest valued attribute for all the models (USD 6.6/year for MNL model and USD 5.7 per year for RPL-I model). High income and/or high education were correlated with substantially higher WTP for most of the service attributes. The results justify the need for giving due consideration to socioeconomic characteristics while formulating measures for improvement of SWM services in an urban area. The estimated WTP values can be used advantageously for quantifying the change in user costs due to change in one or more SWM attributes.

A comparison of several RPL models developed in the present work indicates that parameter richer models are superior in terms of overall goodness-of-fit (i.e. adjusted $\rho^{2}$ value) since it increased from RPLI to RPL-IV model. When number of parameter is same, substantial variation is observed in WTP values obtained from MNL and RPL models. However, no systematic gain or loss is observed in WTP values 
obtained from these two model specifications. The work also demonstrates potential application of RPL models for investigating the effect of socioeconomic attributes on WTP values, and successful application of constrained triangular distribution in RPL models.

\section{References}

Algers S., Bergström P., Dahlberg M. and Dillen J.L. (1998), Mixed logit estimation of the value of travel time, Working paper, Department of Economics, Upsala University, Sweden.

Alpizar F. and Carlsson F. (2001), Policy implications and analysis of the determinants of travel mode choice: An application of choice experiments to Metropolitan Costa Rica, Working paper in Economics, 56, Department of Economics, Göteborg University, Sweden.

Basu D. and Maitra B. (2006), Development of generalized cost model for private car trip makers under traffic information, Journal of Indian Institute of Science, 86, 681-693.

Basu D. and Maitra B. (2007), Valuing Attributes of Enhanced Traffic Information: An Experience in Kolkata, Transport, 22(3), 164-173.

Bhat C.R. (1998), Accommodating variations in responsiveness to level of-service measures in travel mode choice modeling, Transportation Research Part A: Policy \& Practice, 32A, 495-507.

Bluffstone R. and Shazo J.R. (2003), Upgrading municipal environment services to European Union levels: A case study of household's willingness to pay in Lithuania, Environmental Development Economics, 8, 637-654.

Brownstone D. and Train K. (1999), Forecasting new product penetration with flexible substitution patterns, Journal of Econometrics, 89, 109-129.

Caplan A., Grijalva T.C. and Jakus P.M. (2002), Waste Not or Want Not: A Contingent Ranking Analysis of Curbside Waste Disposal Options, Ecological Economics, 43, 185-197.

Carlsson F. (1999), The demand for intercity public transport: The case of business passengers, Thesis, Department of Economics, Göteborg University, Sweden.

Contreras F., Hanaki K., Aramaki T. and Connors S. (2008), Application of analytical hierarchy process to analyze stakeholder's preferences for municipal solid waste management plans, Boston, US, Resources, Conservation and Recycling, 52, 979-91.

Central Pollution Control Board (CPCB) (2000a), Status of Solid Waste Generation, Collection, Treatment and Disposal in Metro Cities, Series: CUPS / 46 / 1999-2000.

Central Pollution Control Board (CPCB) (2000b), Status of Solid Waste Generation, Collection, Treatment and Disposal in Class I Cities, Series: ADSORBS / 31 / 1999-2000

Das S., Birol E. and Bhattacharya R.N. (2008), Informing Efficient and Effective Solid Waste Management to Improve Local Environmental Quality and Public Health: Application of the Choice Experiment Method in West Bengal, India, Environmental Economy and Policy Research, University of Cambridge.

Hasan S., Ukkusuri S., Gladwin H. and Murray-Tuite P. (2011), Behavioral Model to Understand Household-Level Hurricane Evacuation Decision Making, Journal of Transportation Engineering, 137, 341-348.

Hazra T. and Goel S. (2009), Solid Waste Management in Kolkata, India: Practices and Challenges, Waste Management, 29(1), 470-480.

Hazra T. Goel S. and Maitra B. (2013), Willingness-to-pay for Solid Waste Management Service Attributes: Kolkata Municipal Corporation Area, India, as a Case Study, International Journal of Environment and Waste Management, 12(4), 406-421.

Hensher D.A. and Sullivan C. (2003), Willingness to pay for road curviness and road type, Transportation Research D, 8(2), 139-155.

Hensher D.A., Rose J. and Greene W. (2005), Applied choice analysis-A primer. Cambridge University Press, Cambridge, Mass.

http://www.census2011.co.in/census/city/215-kolkata.html

Jin J.J., Wanga Z. and Ran S. (2006), Comparison of contingent valuation and choice experiment in solid waste management programs in Macao, Ecological Economics, 57, 430- 441.

Karousakis K. and Birol E. (2007), Investigating household preferences for kerbside recycling services in London: A choice experiment approach, Journal of Environmental Management, 88(4), 1099-1108. 
Louviere J.J., Hensher D.A. and Swait D.J. (2000), Stated choice methods: Analysis and applications. Cambridge University Press, Cambridge.

McFadden D. and Train K. (2000), Mixed MNL models for discrete response, Journal of Applied Economics, 15, 447-470.

Phanikumar C. and Maitra B. (2010), Modelling generalized cost of travel and its application for improvement of taxies in Kolkata, Journal of Urban Planning and Development, 136(1), 42-49.

Pokhrel D. and Viraraghavan T. (2005), Municipal solid waste management in Nepal: Practices and challenges, Waste Management, 25(5), 555-562.

Revelt D. and Train K. (1997), Mixed logit with repeated choices: Households' choices of appliance efficiency level, Working Paper, Department of Economics, University of California at Berkeley.

Ruud P. (1996), Approximation and simulation of the multinomial probit model: An analysis of the covariance matrix estimation, Working paper, Department of Economics, University of California, Berkeley.

Sakata Y. (2007), A choice experiment of the residential preference of waste management services - The example of Kagoshima city, Japan, Waste Management, 27, 639-644.

Sasao T. (2004), An estimation of the social costs of landfill siting using a choice experiment, Waste Management, 24, 753-762.

Shinkuma T. (2003), On the second-best policy of household's waste recycling, Environmental and Resource Economics, 24(1), 77-95.

Train K. (1998), Recreation demand models with taste differences over people, Land Economics, 74(2), $230-239$.

Train K. (1999), Halton sequences for mixed logits, Working Paper, Department of Economics, University of California at Berkeley.

Train K. (2003), Discrete Choice Methods with Simulation, Cambridge University Press, Cambridge, Mass. 